\title{
Seven Calamities: Insight into the Kara-e Depicted Catastrophes of Japan
}

\author{
Sorina Nicole Fatu ${ }^{\mathrm{a}}$, Lisa Bixenstine Safford ${ }^{\mathrm{a}}$
}

The Seven Calamities (1773, Cleveland Museum of Art) is an emakimono, or Japanese handscroll, created by Nijo Yana during the Edo Period of Japan depicting seven catastrophes that occurred in Japan throughout time. Buddhist Monk Nichiren used the seven calamities found in ancient sutras to explain the disasters agonizing Japan in his time and to stress the importance of following the Buddhist lifestyle. In order to keep the seven calamities at bay, the kings and rulers of Japan were required to recite and teach ancient sutras including the Prajna-Paramita sutra. As the legend tells it, Tathagata — honorific title of a Buddha — had committed this sutra to the kings and rulers because they had requisite power needed to establish the Law of the sutra, unlike the monks and nuns. Had the sutra not been extensively taught to the populace, the seven calamities would befall upon the land and punish the impudent humans that strayed away from Saddharma - Sanskrit for the Correct Law. In essence, it was up to the kings that Tathagata appointed to ensure order and balance to the lands by reciting the Prajna-Paramita. Each of the calamities were painted on paper with black ink, known as sumi-ink, contain ma, which means negative space, and use minimal color. This paper will dissect the history of the seven disasters of Japan and the reasoning behind their occurrence, analyze the use of Japanese sumi-ink combined with the kara-e Chinese style of art, and will contemplate the artist's choice of substituting several of the seven original calamities with his or her own rendition and depiction of sequenced actions.

Keywords: Japan, emakimono, seven calamities, Buddhism, art, sumi-ink, ma, kara-e, history.

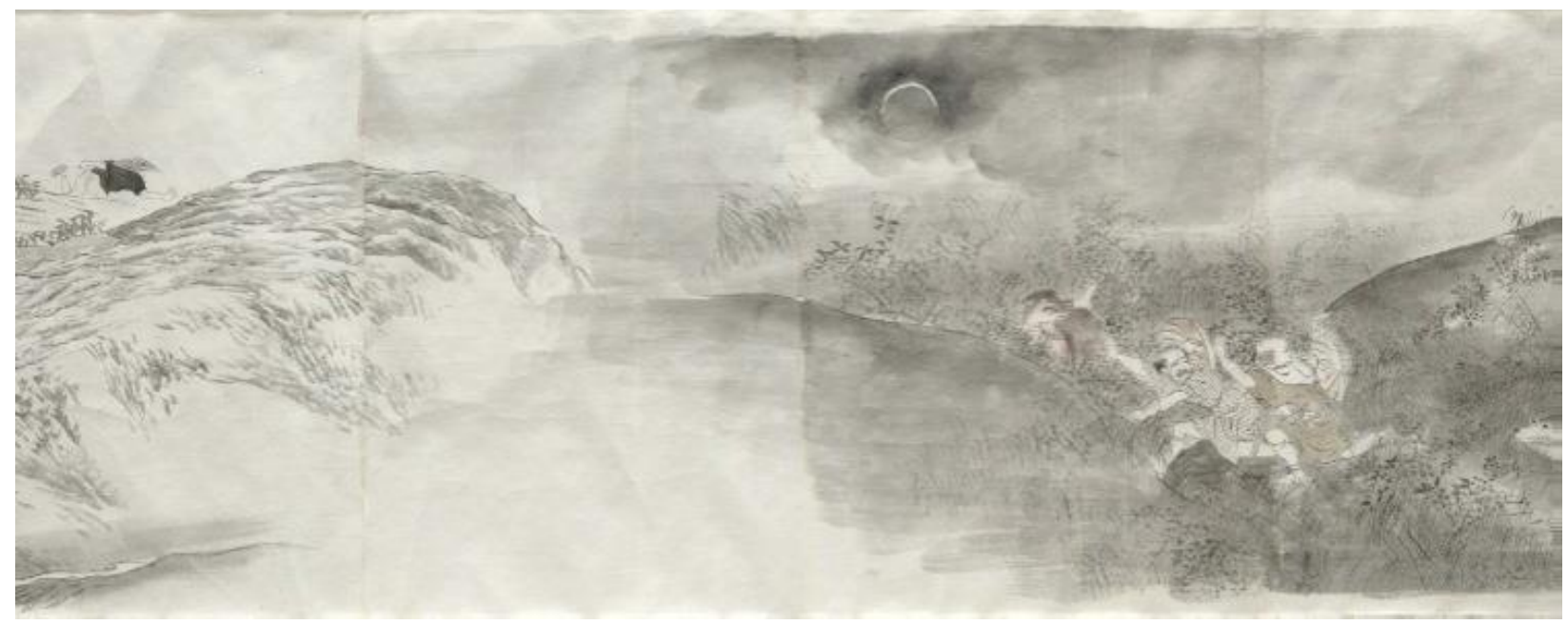

Yana, Nijo. Seven Calamities (detail). 1773. Cleveland Museum of Art.

The Seven Calamities (1773, Cleveland Museum of Art) is an emakimono, or Japanese handscroll, created by Nijo Yana during the Edo Period of Japan. It depicts seven catastrophes that occurred in Japan throughout time. According to Nichiren, a Buddhist monk who lived during the Kamakura Period of Japan, the seven calamities occurred "because both the rulers and the populace turn against the correct teaching." ${ }^{1}$ By correct teaching, Nichiren referred to the proper instruction of the peace of land concept in Buddhism. He used the example of the calamities to present

${ }^{1}$ On Establishing the Correct Teaching for the Peace of the Land (1260 treatise), Nichiren. the inevitable outcome to those who would slander Buddhism and to illustrate the importance of following the Buddhist way without straying afar. The Seven Calamities e-maki is 34.00 centimeters in height and 1714.50 centimeters in width (or 13 $3 / 8$ tall and 675 inches long), ${ }^{2}$ which gives emphasis on how long and disastrous the calamities were over the course of time for the Japanese. The calamities were painted on paper with black ink, known as sumi-ink, and minimal color - the kara-e Chinese inspired ink painting style that originated from the Tang Dynasty of China, though introduced to Japan's

${ }^{2}$ Yana, Nijo. Seven Calamities. 1773. Cleveland Museum of Art. 
Kamakura Period during the Song and Yuan Dynasties. Ma, meaning negative space, is highly represented in most of the calamities. This paper will dissect the history of the seven disasters of Japan and the reasoning behind their occurrence, analyze the use of Japanese sumi-ink combined with the karae Chinese style of art, and will contemplate the artist's choice of substituting several of the seven original calamities with his or her own rendition and depiction of sequenced actions.

In order to have a better understanding and appreciation of the emaki, a further look into what the seven calamities of Japan are is necessary. The original seven calamities, or seven disasters, were written as various sutras. Some examples include the Medicine Master and Benevolent Kings sutras. ${ }^{3}$ The book of Ancient Buddhism in Japan, Volume 1, lists the original seven disasters as followed:

"1) The sun and the moon lose their courses, or their colours change, or they are eclipsed, or surrounded by several haloes.

2) The stars lose their courses, comets appear, the five planets change or appear in the day-time.

3) Naga fire, demon fire, human fire and tree fire, the four great fires, arise and burn down everything. 4) The seasons change: it rains and thunders in winter; there is hoar-frost, ice and snow in summer; it rains earth and stones, sand and pebbles; it hails at wrong times; it rains red or black water; the rivers swell and overflow, carrying stones and rocks along.

5) Heavy storms arise, clouds cover the sun and the moon, houses are destroyed and trees uprooted; sand and stones fly about.

6) Excessive heat causes ponds to dry up, grass and trees to wither and die, and the hundred cereals to remain in a state of unripeness.

7) From all sides enemies come to attack the country; internal and external wars break out, and the hundred families go to ruin and death." 4

In order to keep the seven calamities at bay, the kings and rulers of Japan were required to recite and teach the Prajna-Paramita sutra. As the legend tells it, Tathagata honorific title of a Buddha — had committed this sutra to the kings and rulers because they had requisite power needed to establish the Law of the sutra, unlike the monks and nuns. Had the sutra not been extensively taught to the populace, the seven calamities would befall upon the land.

According to Tathagata, the seven calamities were bestowed upon the lands due to the impudence humans possessed. Impiety was seen among the youth towards their parents, teachers, and their elders, and many rulers and monks strayed away from Saddharma - Sanskrit for the Correct Law. In essence, it was up to the kings that Tathagata appointed to ensure order and balance to the lands by reciting the Prajna-Paramita.

As previously stated, Buddhist Monk Nichiren used the seven calamities found in the sutras to explain the disasters

\footnotetext{
3 "SGI Library Online - The Soka Gakkai Dictionary of Buddhism." SGI Library Online - The Soka Gakkai Dictionary of Buddhism. N.p., n.d.

${ }^{4}$ Visser, Marinus Willem De. Ancient Buddhism in Japan. Leiden: E.J. Brill, 1935. 137-138. Print.
}

agonizing Japan in his time and to stress the importance of following the Buddhist way. Let us take a closer look at who Nichiren was and what form of Buddhism he taught. Nichiren based his teachings on the Lotus Sutra, one of the greatest Mahayana sutras to influence Japan. His belief centered on the idea that all people had an intrinsic, or deep-seated essence of Buddha within themselves and that everyone could be saved by achieving enlightenment in either their present or past life. When one would oppose this Buddhist form for another, or oppose Buddhism as a whole, Nichiren saw this as an absolute deviation from the Buddhist truth and teachings he had cultivated. He strongly believed that his teachings were the universal law, and when one, or many, would deviate from the truth, havoc would arise in Japan, bringing about the deadly calamities. There were several different portrayals of the seven calamities, but the one that Nichiren used most often was the combination of the seven disasters, which included war and natural disasters; the three greater calamities of fire, water, and wind; and the lesser calamities which included the perishing of human society due to high grain prices or inflation, warfare, and pestilence. If all other Buddhist sects were not banished, Nichiren predicted a continuum of disasters. Due to his radicalism, Nichiren's teachings were both influential and controversial. ${ }^{5}$

In the Cleveland Museum of Art, two of the seven calamities were displayed through a pane of glass. Upon seeing this artwork, it was already evident that this was an emakimono, considering its long horizontal portrayal of illustrated narratives that were rolled into a scroll-like formation. Now, in order to understand in what direction the sequence of events is taking place, it is important to know that the Japanese read from right to left, opposite of what is done in the West.

The first panel to the right is shown from a semi-bird'seye view, where the viewer is looking down from above at a massive bird of prey flying off with what appears to be a little girl in its talons. Below the bird, a small house is located in the far right corner. It has a thatched-gabled roof with a spindle wheel peeking out through the left-hand opening. This indicates that this is the home of a peasant or working family. Two people are also depicted running out of the house after the bird. It may be that these are the girl's parents, one reason being that their gestures are exaggerated with limbs reaching out in desperation. Another reason is that one of the characters appears to have prominent male features with their hair tied up, while the other appears more feminine with longer hair that lays flat. It may even be a possibility that they are both male, considering they share bodily similarities, however, the true answer remains with the artist and the interpretation left to the audience.

It is apparent that the abducted child is in fact a young girl and not a male nor adult because if one looks close enough, one can see a faint outline of a doll and several other toys lying on the matt, hinting at her gender. Although airborne, she appears much smaller than the other two people depicted and has a youthful figure with short hair that lays flat. Because her doll and toys appear to be thrown about, she

\footnotetext{
${ }^{5}$ The Rev. Pier Paolo Del Campana, S.J. "Nichiren (Japanese Buddhist Monk)." Encyclopedia Britannica Online. Encyclopedia Britannica, n.d.
} 
may have been snatched while playing outside her home. Upon hearing her cries, her parents ran out of their homes while in the midst of their business, helplessly reaching out for their daughter.

Surrounding the house is a kara-e Chinese-style landscape containing small trees, grasses, cliffs, and a bridge that are all detailed in Japanese sumi-ink. An important asset to this painting is the ma, or space, that is washed over with uneven strokes of a gray wash, symbolizing the turmoil within the calamity. The ma may even represent the clouds, ground, and eerie mist, which was a popular use for ma in the Muromachi, Momoyama, and Edo Periods of Japan. Very minimal coloration of brown and dark green is depicted with the washes of gray. Within the ma is where the massive bird of prey flies, carrying the young girl in its talons, making them stand out more prominently. The bird looks similar to a hawk or an eagle and is the darkest figure depicted; shown to have dark colored washes of brown and grey, outlined in thick strokes of black ink with a very minimal light-wash that separates the dark pattern. This could easily signify that the bird is the main focus of the calamity.

If one is very observant, one will notice that the ma surrounding the bird is of a darker shade of gray wash when compared to the surrounding ma. Whether or not it was Yana's intention to create a darker ma surrounding the bird of prey, it bears a shadow of darkness that corrodes those in its presence. The combination of a dark-washed, black sumi-ink bird with corresponding dark ma indicates that the bird is the cause of terror and distress besetting the people.

What is most interesting about this scene is the pronounced coloration of the little girl taken away in flight. The entire scene is painted with a combination of dark grays, blacks, and neutral colors, however, the girl is wearing a red garment. Even her supposed parents are so neutral that one could barely tell they are present. It is as if the artist is indicating that all else is irrelevant to the image. The focus lies on the enormous bird and the young girl. The parents are helpless, and so they are blended in with the chaos depicted.

Another interesting detail is that along with the red coloration of the girl's garment, part of a tree located on the far right-hand side of the panel is colored in a similar shade of red. It is very curious why the artist chose to add the red hue to a tree. One may speculate that the red leaves of the tree symbolized autumn, yet I believe that the artist was conveying a different message. The tree is shown to be growing on the right side of the house with the trunk hidden, creating the illusion that the tree stemmed from within the home of these unfortunate people. The majority of the leaves are colored red, while a smaller portion of the bottom half is colored in different shades of gray. Because the red is present on both sides of the panel, the artist may have wanted to display bloodlust, pain, and suffering hindering not only the young girl, but hindering the family as well. Both ends are tainted and effected. And perhaps this family was not innocent to begin with, hence the partial red tree that appears to stem from within the home of this family. It may even be that the family's sins were being atoned for with the capture of their daughter.

The second panel presents a landscape scene where an image of two men running away from two wolves is depicted. The image is presented in a different view than the last calamity, where here we are looking at the image as if it is happening right in front of us, rather than below us, viewed from above. The use of sumi-ink is much more prevalent, with no coloration, except for washes of various gray tones. Similar to the last calamity, a landscape is depicted. Fine ink details are presented in thin and tall grasses, while cliffs are carefully detailed with the use of the kara-e style sumi-ink. The men appear to be running towards the cliffs, since they are located on the right of the image facing left. What is very interesting about this image is that the area surrounding the cliffs has no dark gray wash. The ma presented is almost entirely white, and it seems that the artist has done this on purpose. When the panel is viewed as a whole, there is a deliberate dark line separating the area between the wolves and the area of the cliff. Just as in the other image, where the giant bird of prey was entirely surrounded by a dark wash of gray, the wolves are surrounded by the darkest wash of gray. This signifies how they bring the calamity upon these two men. Even the moon is depicted with a dark grey, almost black, wash of ink, indicating that no light or hope is to be present during these calamities. Or perhaps the men have brought the darkness upon themselves, though it is curious that they have light features which stand out among the grey ma. This may signify that even the innocent were victims among the catastrophes.

Although the other five panels of the scroll were not displayed, they were accessible on the Cleveland Museum of Art webpage. Several other depictions of animals attacking humans are shown, one being a giant snake attacking what appear to be travelers. Other disasters that closely resemble the original seven calamities as described in ancient sutras were depicted as well, such as the outbreak of war and fighting among the people and great fires engulfing villages that burned everything down. Upon looking at all seven calamities, I was left wondering why Yana chose to replace some of the original disasters with renditions of his own. Many reasons can account for this, but I believe that the artist wanted to depict scenarios in which nature fought back against the humans. As learned from the original seven calamities and Nichiren's rendition, the calamities fell upon Japan due to impudence, impiety, and failure to respect Buddhist teachings. Among these teachings were the belief that everything is connected and that nature should be respected, considering we are all natural beings of the world. Due to the lack of respect of nature, animals, and the landscape surrounding the Japanese people, the artist may have wanted to depict scenarios in which humans atoned for their sins by being attacked by what they disrespected most. As a result, the animals attacked.

Over the course of time, Japan has been influenced by many cultures of the West. China, one of Japan's closest neighboring countries, has always played a tremendous role in influencing the art and culture of Japan. Techniques seen in Chinese landscape paintings from the Tang, Song and Yuan Dynasties of China had traversed to Japanese style paintings. Among the techniques were sumi-ink, the kara-e style, and the use of ma, as seen in the Seven Calamities. This combination of the kara-e, sumi-ink and ma style were important for conveying messages of energy and spiritual journeys, and most importantly, representing the significance of the nature surrounding us. Considering the Japanese believed in similar principles of nature, spirituality, and meditation, they too adopted these styles and implemented 
them into their paintings. Nijo Yana used kara-e, sumi-ink, and ma to convey and illustrate the messages of old Buddhist teachings that were most likely prominent stories told in the Edo Period. Thus, the Seven Calamities serves as a reminder to the Japanese that impudence and dishonor may result in catastrophic events.

\section{References}

Mason, Penelope E. History of Japanese Art. New York: Abrams, 1993. Print.

Nichiren. "On Establishing the Correct Teaching for the Peace of the Land." N.p., 16 July 1260. Web. 13 Mar. 2014.

The Rev. Pier Paolo Del Campana, S.J. "Nichiren (Japanese Buddhist Monk)." Encyclopedia Britannica Online. Encyclopedia Britannica, n.d. Web. 13 Mar. 2014.
"Rissho Ankoku--"On Establishing the Correct Teaching for the Peace of the Land"" Home. N.p., n.d. Web. 13 Mar. 2014.

"SGI Library Online - The Soka Gakkai Dictionary of Buddhism." SGI Library Online - The Soka Gakkai Dictionary of Buddhism. N.p., n.d. Web. 13 Mar. 2014.

Taisho, trans. Kubo, Tsugnari and Yuyama, Akira. "The Lotus Sutra." BDK English Tripitaka Series. 9. 262. Numata Center for Buddhist Translation Research, 2007. Print.

Visser, Marinus Willem De. Ancient Buddhism in Japan. Leiden: E.J. Brill, 1935. 137-138. Print.

Yana, Nijo. Seven Calamities. 1773. Cleveland Museum of Art. N.p., n.d. Web. 13 Mar. 2014. 